\title{
Seasonal monitoring of microbiological air contamination from a museum - a case study
}

\author{
Iuliana Pamela Scarlat ${ }^{1,2^{*}}$, Veronica Lazăr $^{2}$, Raluca Stepa $^{1}$, Mariana Carmen Chifiriuc ${ }^{2}$ \\ Lia-Mara Dițu², and Maria Haiducu ${ }^{1}$ \\ ${ }^{1}$ The National Institute of Research and Development on Occupational Safety "Alexandru Darabont" \\ Bucharest, Laboratory Chemical and Biological Risks Bucharest, Romania, \\ ${ }^{2}$ University of Bucharest, Department of Microbiology, Faculty of Biology, Bucharest, Romania
}

\begin{abstract}
The aim of this study was to monitor microbial contamination in the work place of a museum, for estimating the influence of seasons, microclimatic parameters and tourists. The analysis was carried out in artefacts deposits, restoration laboratories and exhibition spaces. The media used to demonstrate the presence of biological agents, nonpathogenic and with pathogenic potential (opportunistic bacteria and filamentous fungi with haemolytic properties) were: simple agar, blood agar and Sabouraud with chloramphenicol. The isolated bacterial strains were identified by API tests and the fungal strains by examination of features with taxonomic value, aspects based on macroscopic observations of colony/cultures and microscopic assessment of mycelia. The counts of the microorganisms in the air were higher especially in the textiles deposits (the mesophilic microorganisms ranged from 200 to $1.4 \times 10^{4} \mathrm{CFU} / \mathrm{m}^{3}$ ). The filamentous fungi most frequently isolated species were: Aspergillus spp.; Penicillium spp., Cladosporium spp. The most frequently isolated bacteria swere: Staphylococcus (S. epidermidis, S. xylosus, S. capitis); Bacillus (B. cereus, Bacillus spp). The results of this study indicate a microbial air load containing both filamentous fungi and bacteria strains, including some opportunistic pathogens which can represent a health risk for the museums workers, especially in the seasons with higher exposure.
\end{abstract}

\section{Introduction}

Museums and the heritage deposits store, exhibit and sometimes preserve and restore old and valuable objects which can have a high degree of microbial contamination and degradation. The personnel involved in the surveillance, manipulation and restoration are exposed to microbiological health risk factors, which have to be monitored and reduced as much as possible.

According to the National Statistics Institute (INS), in Romania, in 2014 there were 739 museums and public collections with $10,823,706$ visitors [1]. In these institutions 6,554 employees work, of which: 1178 museum curators; 501 conservation workers; 390

" Corresponding author: scarlatpamela@yahoo.com 
restorers; 258 researchers; the rest is accounted for by administrative staff/ supervisors (INS/ 2015).

The museum selected for monitoring is situated in a historical building, constructed at the end of the XIX century and is one of the most visited Romanian museums all year round, the highest number being during summer vacation. This museum has its own storage spaces for exhibits, not all of them in the main building of the museum, but in the same area.The weather in the museum's area is cold and moist: multi-annual average temperature is $8^{\circ} \mathrm{C}$ and the average humidity is between $71 \%$ and $76 \%$ [2]. The building is surrounded by a lot of vegetation.

The number and type of microorganisms are influenced by the presence of nutrients in the contaminated objects and by temperature, humidity and seasons [3]. The present study investigated these influences on the microbiological contamination of air. These aspects are important because they may also impact the heath of museum employees, besides affecting patrimonial artefacts.

\section{Materials and methods}

Sampling was done in seasonal dynamics during one year, collecting a total of 420 samples, 105 samples per season. Each season the sampling was done in the same places: 10 heritage deposits (for decorative art objects, archives, and warehouses of furniture, paintings or other heritage objects) and 25 museum exhibition rooms; of these 25 rooms, in ten of them the access of visitors is forbidden, only watching from the doorway being allowed.

Microbiological sampling was performed according to EN 14042:2003, with the device SAS Super Sampler 100, for one minute per sample, with a flow rate of 100 1/min [4].

The culture media used for sampling and culturing were specific for development of mesophilic biological agents, i.e., haemolytic bacteria and microfungi: simple agar, blood agar and Sabouraud with chloramphenicol, respectively.

Microbial counting was conducted using the automated colony counter 300 SCAN, the correction being performed according to the chart sampler with 219 holes in $90 \mathrm{~mm}$ Petri dishes.

The calculation formula:

$$
X=\frac{\operatorname{Pr} \times 1000}{\mathrm{~V}}
$$

$\mathrm{V}=$ volume of air sampled;

$\mathrm{r}=$ number of the counted colony forming units (C.F.U.);

$\operatorname{Pr}=$ probable number of holes obtained by positive correction;

$\mathrm{X}=$ number of C.F.U / 1000 litres of air.

The measured values of total mesophilic bacteria and filamentous fungi have been compared to those specified in the European Collaborative Action - Indoor Air Quality \& ITS Impact on Man (ECA-IAQ) [5], as recommended limit values according to tables 1 and 2 respectively.

Table 1. The recommended values for mesophilic bacteria according to ECA IAQ

\begin{tabular}{|l|c|c|}
\hline \multicolumn{1}{|c|}{ Category } & Homes & Non industrial indoor environments \\
\hline Very low & $<100$ & $<50$ \\
\hline Low & $<500$ & $<100$ \\
\hline Intermediate & $<2500$ & $<500$ \\
\hline High & $<10000$ & $<2000$ \\
\hline Very high & $>10000$ & $>2000$ \\
\hline
\end{tabular}


Table 2. The recommended values for fungi according to ECA IAQ

\begin{tabular}{|l|c|c|}
\hline \multicolumn{1}{|c|}{ Category } & Homes & Non industrial indoor environments \\
\hline Very low & $<50$ & $<25$ \\
\hline Low & $<200$ & $<100$ \\
\hline Intermediate & $<1000$ & $<500$ \\
\hline High & $<10000$ & $<2000$ \\
\hline Very high & $>10000$ & $>2000$ \\
\hline
\end{tabular}

API biochemical tests (BioMerieux, France) were used to identify the isolated bacterial strains. Fungal taxonomic units/at genus level were identified based on macro- and microscopic mycelia assessment.

Measurement and calculation of the parameters of the microclimate were performed according to EN 27243:1996 - "Warm ambience. Estimation of the thermal stress on working of human in WBGT index (wet temperature and globthermometer)" [6]. For the determination of the physical parameters were used: for dry air temperature $\left({ }^{0} \mathrm{C}\right)$ measuring the digital camera model HYGRO-THERMOMETER HTA 4200; for air speed $(\mathrm{m} / \mathrm{s})$ digital camera sensor SUPER SCIENTIFIC DIGITAL hand TERMOANEMOMETER 840030.

\section{Results and Discussion}

\subsection{Microbiological assay}

\subsubsection{Quantitative analysis}

The analysed samples revealed a high level of the air contamination in almost all the rooms where measurements were performed.

The minimum and maximum values as well as standard deviation of air microbial contamination are shown in Table 3.

Table 3. The range of microbiological contamination levels in the museum.

\begin{tabular}{|l|c|c|c|c|c|}
\hline \multicolumn{1}{|c|}{ Microorganisms } & $\begin{array}{c}\text { No of } \\
\text { samples }\end{array}$ & $\begin{array}{c}\text { Minimum } \\
\text { values } \\
{\left[\mathbf{C F U} / \mathbf{m}^{3}\right]}\end{array}$ & $\begin{array}{c}\text { Maximum } \\
\text { values } \\
{\left[\mathbf{C F U} / \mathbf{m}^{3}\right]}\end{array}$ & $\begin{array}{c}\text { Standard } \\
\text { deviation }\end{array}$ & $\begin{array}{c}\text { Percentile } \\
\mathbf{( 9 0 \% )}\end{array}$ \\
\hline mesophilic & 415 & 200 & $1.4 \times 10^{4}$ & $3.2 \times 10^{3}$ & $4.6 \times 10^{2}$ \\
\hline haemolytic bacteria & 415 & 20 & 350 & 83 & 273 \\
\hline fungi & 415 & 170 & $3 \times 10^{3}$ & $9 \times 10^{2}$ & $2.6 \times 10^{3}$ \\
\hline
\end{tabular}

The standard deviation for mesophilic bacteria and haemolitic bacteria is quite high, showing a large variation in the number of $\mathrm{CFU} / \mathrm{m}^{3}$ for these type of microorganisms. In the case of fungi there is a smaller variation.

The variation of air microbial contamination level values in each season and type of room (with full access/ doorway watching/deposit) are presented in figures 1, 2 and 3 for each type of monitored microbial groups. 


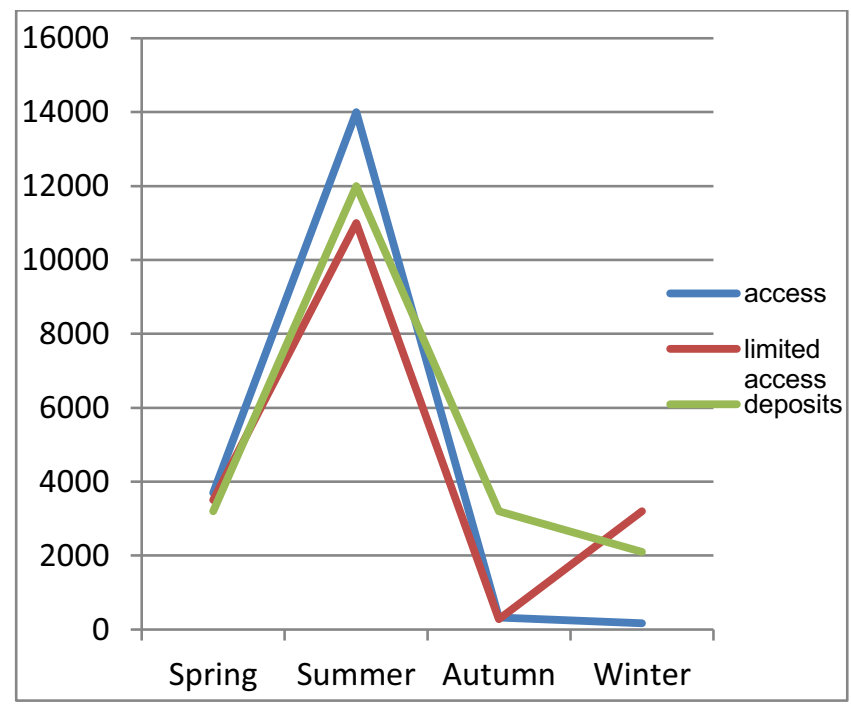

Fig. 1. The seasonal variation of airborne mesophilic bacteria (number of C.F.U /1000 l of air) in different museum spaces.

Concerning the seasonal variation of mesophilic bacteria, the highest values of indoor air contamination (correlated with the outdoor one) have been registered during the summer, in all analysed spaces. This may be explained by their resistance to high temperatures, especially Gram positive ones (see the qualitative analysis): the bacilli and clostridia which produce endospores; the staphylococci, non-spore forming bacteria, are also present but with a natural resistance in environment.

In general, the concentration of mesophilic bacteria was higher in the rooms with full visitor access than in those with limited access. This may show a relation between the presence of visitors (particularly numerous in summer) and the level of air contamination.

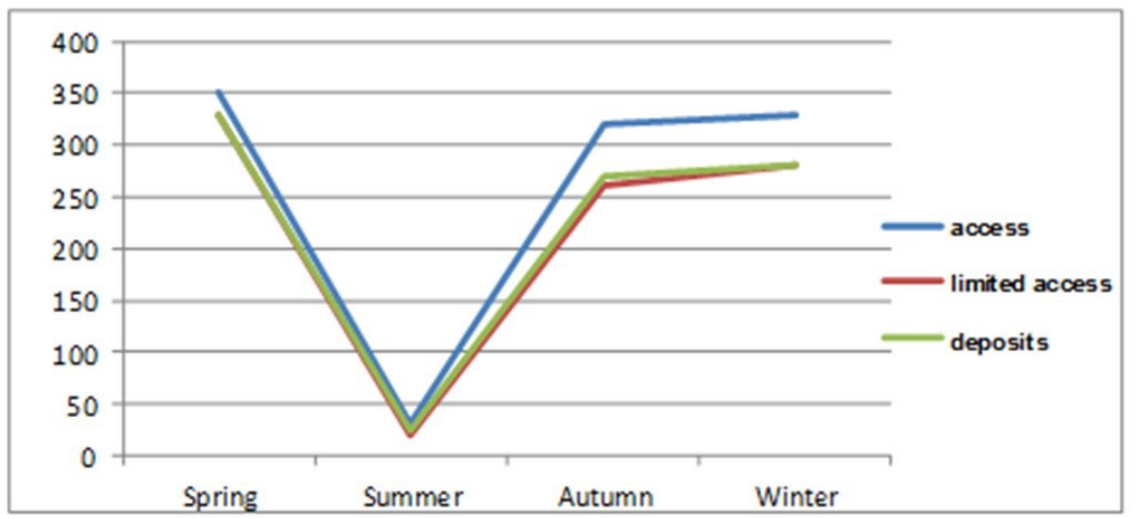

Fig. 2. The seasonal variation of haemolytic microorganisms counts (number of C.F.U / 10001 of air) in different museum's spaces.

Contrary to mesophilic bacteia, the seasonal variation of haemolytic microorganisms shows that the values of indoor air contamination (mainly correlated with the upper respiratory tract of human carriers) have been the lowest during summer, in all analysed spaces, which may explained by their susceptibility at high and dried temperatures and by the decreased cases of visitors with seasonal respiratory problems during summer. 


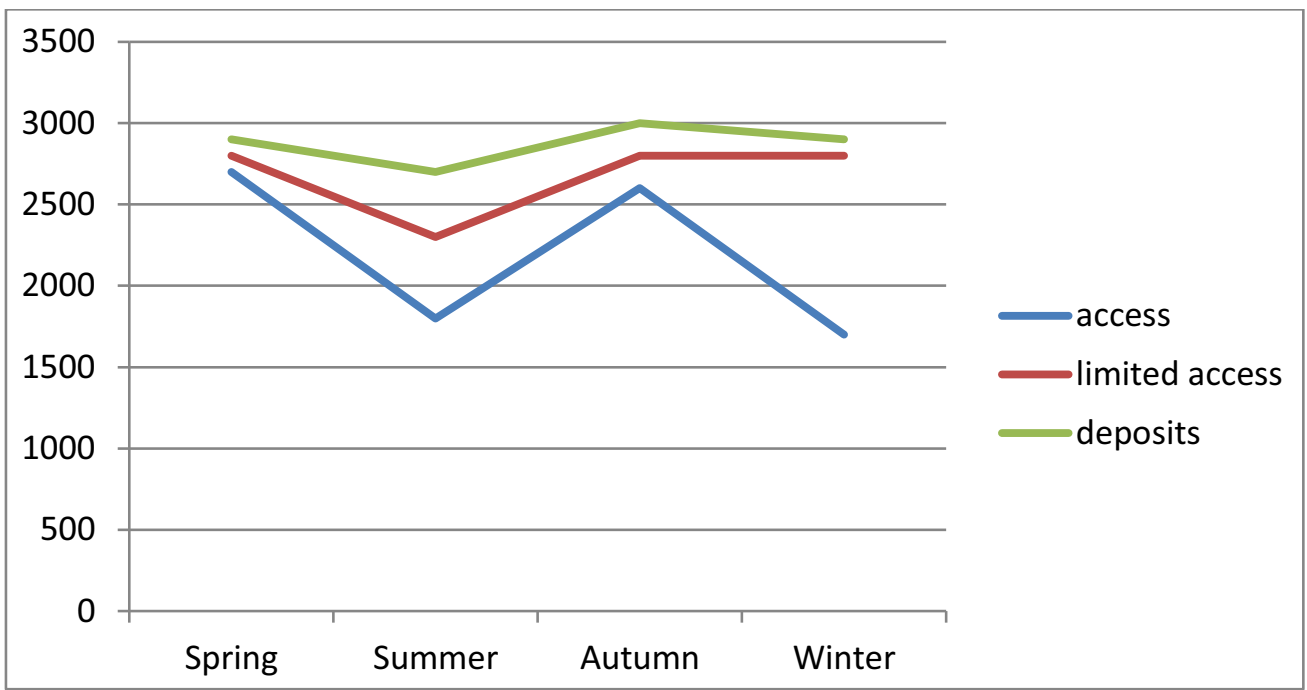

Fig. 3. The seasonal variation of filamentous fungi counts (number of C.F.U / 10001 of air) in different museum spaces.

Concerning the seasonal variation of microfungi, the highest values of indoor air contamination (correlated with the outdoor one, but also with the contaminated exhibits) have been observed during spring and autumn, in all analysed spaces, values correlated with the air humidity during these seasons; the microfungi are resistant at hot and dried temperatures, but their growth is favoured by humidity too, and this condition seems to be accomplished in deposits and rooms with limited access of visitors, probably due to a bad ventilation.

\subsubsection{Qualitative analysis}

Concerning the bacterial strains isolated from the analysed air samples, it was found that $80 \%$ of them are Gram - positive bacteria, the most common isolates belonging to some species of the genera Bacillus (B. cereus and other species); Clostridium, Staphylococcus (S. epidermidis, S. xylosus, S. capitis) and Cellulomonas spp. Among the Gram - negative bacteria, the most frequently identified belong to the genus Pseudomonas (P. fluorescens and other species). The Gram -positive bacteria are more specific to indoor environment, while the Gram- negative ones are specific to external environment, according to some authors [7].

For the filamentous fungi, the most frequently isolated strains belong to: Aspergillus spp.; Penicillium spp., Cladosporium spp., Alternaria spp. and Rhizopus spp.

\subsection{Variation of the microclimate parameters on the air museum microbiological quality}

Microclimate parameters were monitored in the same rooms and the same period in which microbiological sampling were carried out. Average values of microclimate parameters depending on room type are presented in table 4. 
Table 4. The range of the microclimate parameters from museum

\begin{tabular}{|c|c|c|c|c|c|}
\hline \multirow{2}{*}{ Season } & \multirow{2}{*}{ Type of room } & \multicolumn{4}{|c|}{ Microclimate parameters } \\
\cline { 3 - 6 } & & $\begin{array}{c}\text { Minimum } \\
\text { values }\end{array}$ & $\begin{array}{c}\text { Maximum } \\
\text { values }\end{array}$ & $\begin{array}{c}\text { Minimum } \\
\text { values }\end{array}$ & $\begin{array}{c}\text { Maximum } \\
\text { values }\end{array}$ \\
\cline { 3 - 6 } & access & 17.8 & 18.2 & 55 & 55 \\
\cline { 2 - 6 } & limit access & 17.8 & 18 & 55 & 55 \\
\cline { 2 - 6 } & deposits & 9.3 & 10.5 & 73.7 & 74.3 \\
\hline \multirow{3}{*}{ Spring } & access & 20.8 & 21.4 & 52.7 & 53.8 \\
\cline { 2 - 6 } & limit access & 20.7 & 21.3 & 51.7 & 52.2 \\
\cline { 2 - 6 } & deposits & 29 & 30.7 & 73.7 & 74.3 \\
\hline \multirow{3}{*}{ Summer } & access & 20.8 & 21.2 & 53.8 & 54.2 \\
\cline { 2 - 6 } & limit access & 21 & 21 & 54 & 54 \\
\cline { 2 - 6 } & deposits & 26.9 & 27.2 & 72.8 & 73.1 \\
\cline { 2 - 6 } & access & 16.8 & 17.3 & 55 & 55 \\
\hline \multirow{2}{*}{ Winter } & deposits & 6.8 & 7.2 & 75.8 & 76.3 \\
\hline
\end{tabular}

The micro-climate parameters do not have large variations in the museum rooms (with full or limited access) or in the deposits. This may indicate that they have a small influence on the variation of the microbiological air load. However, when comparing room with deposits, it can be seen there are difference of $10{ }^{\circ} \mathrm{C}$ for temperature and $20 \%$ for humidity, which may explain why in deposits the number of fungi colonies is higher.

The high number of $\mathrm{CFU} / \mathrm{m}^{3}$ for all species in the present study confirms the findings of other researchers that the museum environment is favourable for the growth of microorganisms, ensuring conditions for survival and propagation an environment with high humidity and a nutrients [8], particularly the patrimony objects of textile and leather being a growth supportive substratum for developing moulds and bacteria [9, 10]. According to the results of the quantitative analysis the recommended limits have been exceeded in almost all deposits but also in many of the rooms with full visitors access. This can represent a serious risk to the health of the museum and deposit personnel.

The species identified were Bacillus spp. (B. subtilis, B. cereus), Staphylococcus spp., Streptococcus spp., Enterobacter cloacae, Pseudomonas fluorescens, and Clostridium beijerinckii.

Genera as Bacillus, Staphylococcus, Streptococcus were isolated by other authors in museums, libbers and archive indoor environment [1, 9, 11-12]. 
Genera as Aspergillus spp.; Penicillium spp., Cladosporium spp., Alternaria spp, and Rhizopus spp. were isolated also by other authors in museums or similar spaces [12-13].

The species accounting for mycological contamination of the air from museums and heritage deposits are Aspergillus spp.; Penicillium spp., Cladosporium spp., Alternaria spp, Rhizopus nigricans; these are also known as an etiological factor of several allergic diseases [14-15].

There are many studies that show the link between exposure of workers to bioaerosols and occupational diseases [16-17]. However there are very few studies that have been done a seasonal monitoring. Such studies are however important since they may contribute to a better understanding of the phenomena that cause patrimonial degradation and may also cause occupational diseases; they will also help to establish occupational exposure limit values of workers.

\section{Conclusions}

The study shows there are seasonal variations in the microbiologic air contamination, especially for mesophilic bacteria and hemolytic bacteria and to a lesser extent for fungi. Since the micro-climate parameters are quite stable their influence may be assumed to be limited. The influence of the seasons themselves (weather, life cycle) and the seasonsal variation of tourists (more numerous in summer) may have a more important influence on microbiological contamination of the air in teh museum.

The present study highlighted a high level of mesophilic microorganisms recorded in the summer in the monitored museum rooms which can be explained by the large number of tourists and the rich vegetation of the close surrounding area.

The highest level of haemolytic microorganisms was recorded in spring, in areas with tourists access, their strong influence on the results being explained by the high rate of respiratory opportunistic infections and carriers too of such infectious agents during this season.

The maximum levels of air pollution were found in the heritage deposits (those outside the museum building). It can be seen that in these deposits the relative humidity is quite high which favours the growth and multiplication of microorganisms, especially microfungi. Aspergillus and Penicillium are the most frequently identified microfungi. Aspergillus niger is associated with onychomycosis [18], skin infections [19] but there are also some reports on lung diseases.

The variation of the amount of aeromicroflora may be very fast, depending on environmental conditions and the life cycle of organisms, making it difficult to establish a medium level of exposure and thus a limit value of occupational exposure.

This work was funded by the ANCS, PN-II-PT-PCCA-2011-3-1742 project, "Improvement of occupational environment quality in cultural heritage deposits. Validation of gamma radiations treatment of textile and leather cultural goods (TEXLECONS)" contr. no. 213/2012.

\section{References}

1. National Statistical Institute, Units cultural and artistic activity in 2014 (2015)

2. https://romanian.wunderground.com

3. B. Gutarowska, J. Skóra, K. Pielech-Przybylska, Aerobiologia, 33-44 (2015)

4. EN 14042:2003, Workplace atmosphere - Guide for the application and use of procedures for the assessment of exposure to chemical and biological agents

5. EUR 14988 EN, Commission of the European Communities, Biol. Particles in indoor environments, 12 (1993) 
6. EN 27243:1996, Warm ambience. Estimation of the thermal stress on working of human in WBGT index (wet temperature and globthermometer)

7. H. Aydogdu, A. Asan, M. T. Oktun, Environ. Monit. Assess., 53-66 (2010)

8. J.P. Brown, B.W. Rose, APT Bulletin, 27 (1996)

9. S. Fekadu Hayleeyesues, A. M. Manaye, Asian Pac J Trop Biomed, S312 - S317 (2014)

10. M. Lazaridis,E. KatsivelaI, I. Kopanakis, L. Raisi, G. Panagiaris, Heritage Science, 3-34 (2015)

11. J. Skóra, B. Gutarowska, K. Pielech-Przybylska, Ł. Stępień, K. Pietrzak, M. Piotrowska, P. Pietrowski, Aerobiologia, 389-401 ( 2015)

12. J. Mandal, H. Brandl, The Open Environm \& Biol. Monitoring Jour., 83-96 (2011)

13. M. L. Grbic, M. Stupar, J. Vukojevic, I.Maricic, N. Bungur, Arch. Biol. Sci., 955-962 (2013)

14. M. Z. R. Gomes, R.E. Lewis, D.P. Kontoyiannis, Clin. Microbiol Rev. 411-445 (2011)

15. H. Bouziane, J.P. Latgé, C. Fitting, S. Mecheri, M. Lelong, B. David, Allergol. Imunopathol., 33 (2005)

16. J. Skóra, K. Zduniak, B. Gutarowska, D. Rembisz, Med Pr., 153-65 (2012)

17. P. Eggleston, K. Bush, J. Allergy Clin Immunol, 403-405 (2001)

18. J. Araiza, P. Cansesco, A. Bonfaz, PubMed,251-254 (2006)

19. KW. London, A.P. Coke, J.P. Burnie, AJ Oppenheim, C.Q. Morris, PubMed, 191-198 (1996) 